\title{
Modeling the Formation of Alkali Aluminosilicate Gels at the Mesoscale Using Coarse-Grained Monte Carlo
}

\author{
Kengran Yang ${ }^{1}$ and Claire E. White ${ }^{1 *}$ \\ ${ }^{1}$ Department of Civil \& Environmental Engineering and Andlinger Center for Energy \\ and the Environment, Princeton University, Princeton, USA \\ * Corresponding author: Phone: +1 609258 6263, Fax: +1 609258 2799, Email: \\ whitece@princeton.edu \\ Postal address: Department of Civil \& Environmental Engineering, Princeton \\ University, Princeton NJ 08544, USA
}

\section{Supporting Information}

\section{Energy Evolution of the CGMC Simulations}

Fig. S.1 shows the evolution of Gibbs free energy for the six AAM systems investigated in this study. It is seen in general that the energy of all six systems decreases with the number of iteration, and gradually reaches steady state. Note that for systems activated by sodium silicate $(\mathrm{H} / \mathrm{S}$ - and S-activated), there is a sharp increase in the energy at $\sim 0$ iterations, which is due to the switch from preequilibration of free silica in the activating solution to dissolution of precursor particles (the actual "start" of the alkali-activation reaction). 
(a)

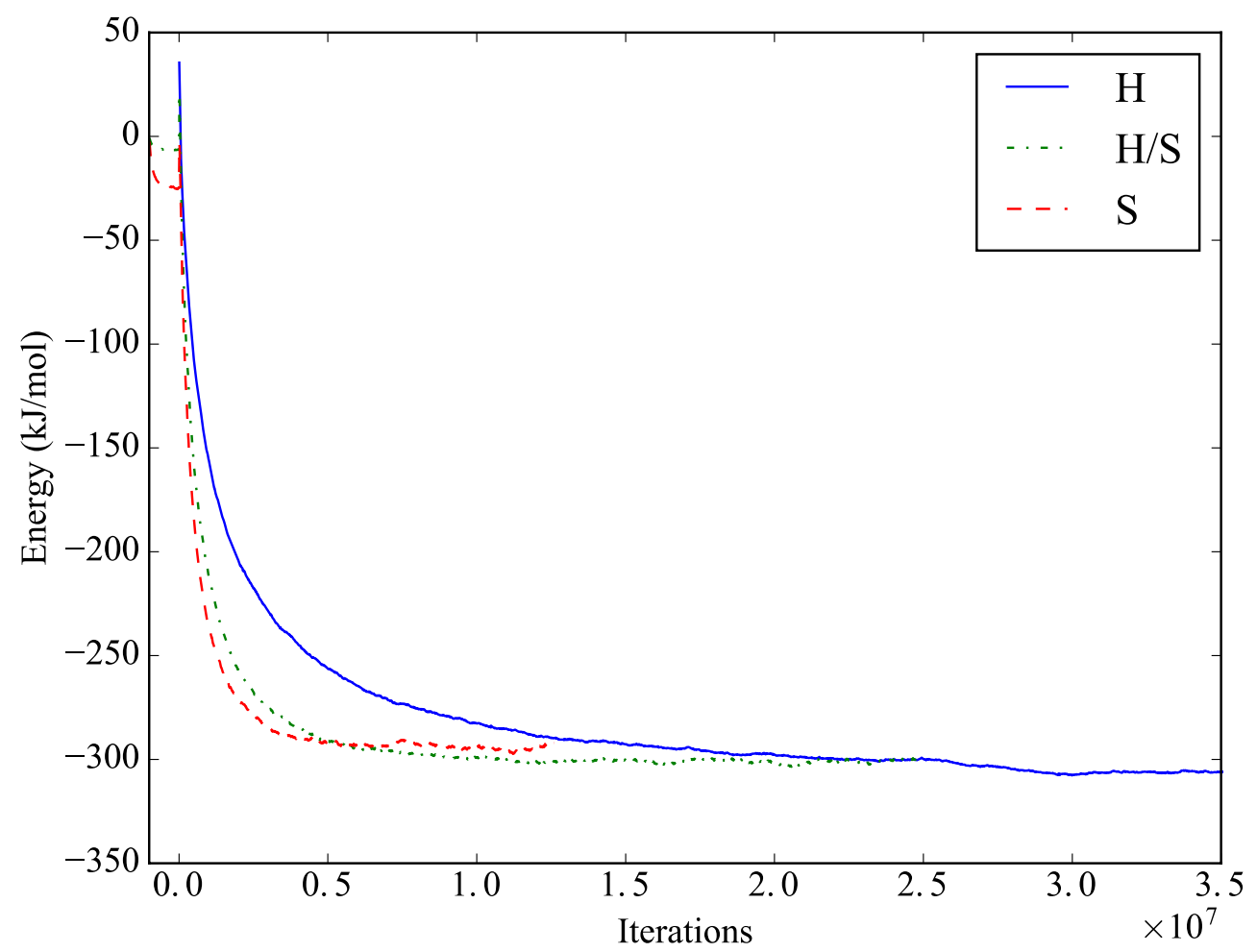

(b)

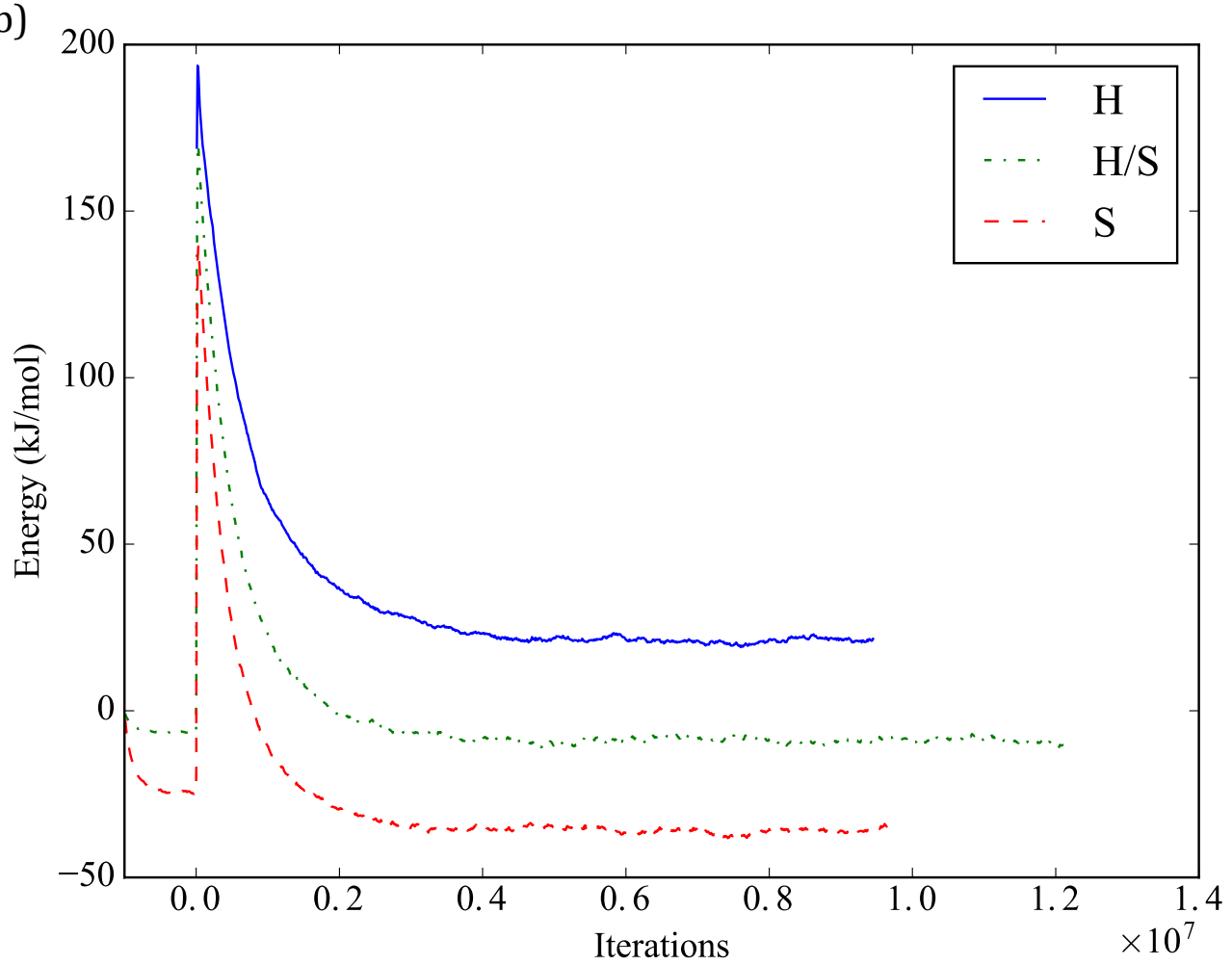

Figure. S.1. Energy evolution of (a) metakaolin, and (b) fly ash activated with H-, H/S- and S-based solutions. 
Evolution of the Percentage of Monomers as an Indication of the Extent of Reaction

Since the percentage of monomers in the AAM system is a good indicator of the extent of the alkali-activation reaction (i.e., the amount of monomers increases during dissolution, and decreases during condensation), the evolution of the percentage of monomers in the metakaolin-based systems with a linear x-axis (in contrast to Fig. 2 of the main article where the x-axis is a log scale) is plotted in Fig. S.2, serving as a comparison to the heat evolution data from the ICC study of Zhang et al. ${ }^{1}$ It is observed that both data are able to reveal the dissolution peak, that is, the sharp spike at the very beginning of the reaction. The ICC data also shows a broad peak after the spike, which indicates the condensation of the AAM gel. However, the condensation peak is less obvious in Fig. S.2, which is probably due to the relatively artificial diffusion mechanism implemented in the CGMC model. Fig. S.2 also shows that the condensation peak intensity decreases with increasing $\mathrm{Si} / \mathrm{Al}$ ratio, which is consistent with the ICC data.

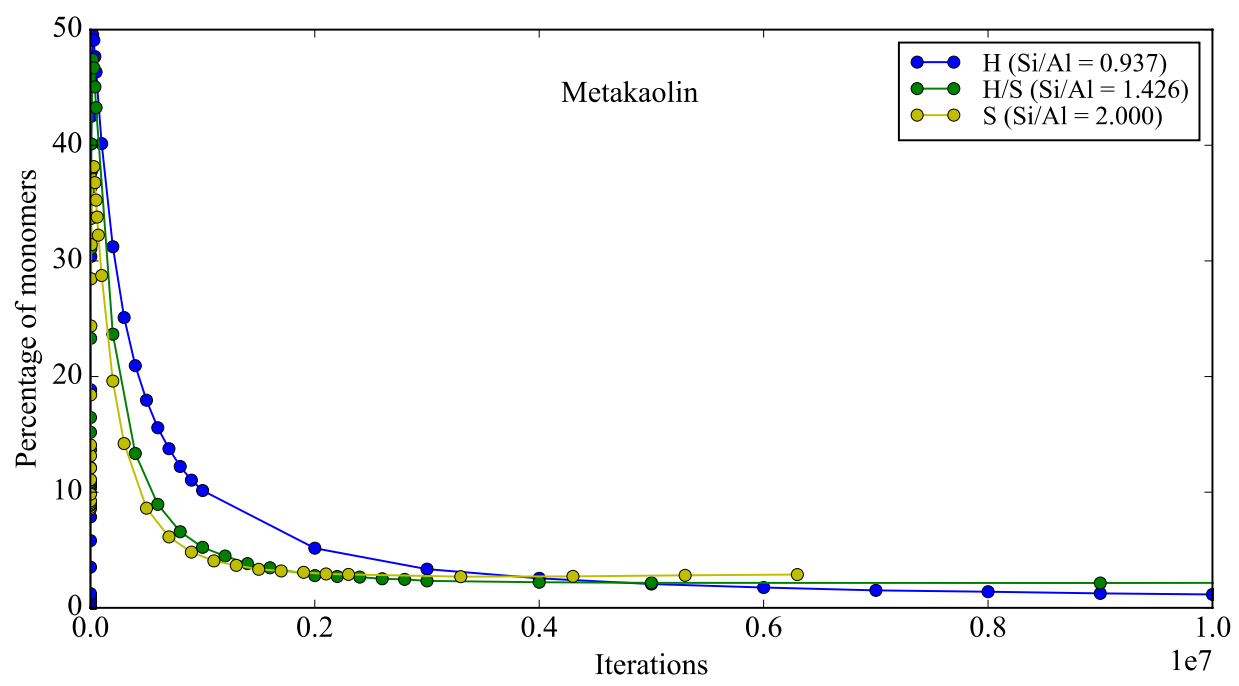

Fig. S.2. Evolution of percentage of monomers as a function of the iterations for the metakaolin-based systems. 


\section{Pore Solution Chemistry of AAM Gels}

In the main article the pore solution chemistry was analyzed assuming that monomers in the solution are indicative of the overall dissolved species. Another plot of concentration of dissolved species in the pore solution at the end of the simulation for all systems (H-, H/S- and S-activated; metakaolin and fly ash) is shown in Fig. S.3. Here the dissolved species are defined as monomers and oligomers consisting of less than or equal to 20 monomeric units. It can be seen that the pattern is quite similar to Fig. 3 in the main article, except that here the alumina content of the two precursors does not match up at $\mathrm{Si} / \mathrm{Al}$ ratio of 2.0 , indicating that there are slightly more alumina sites in the oligomers in the pore solution of the fly ash-based system compared with metakaolin.

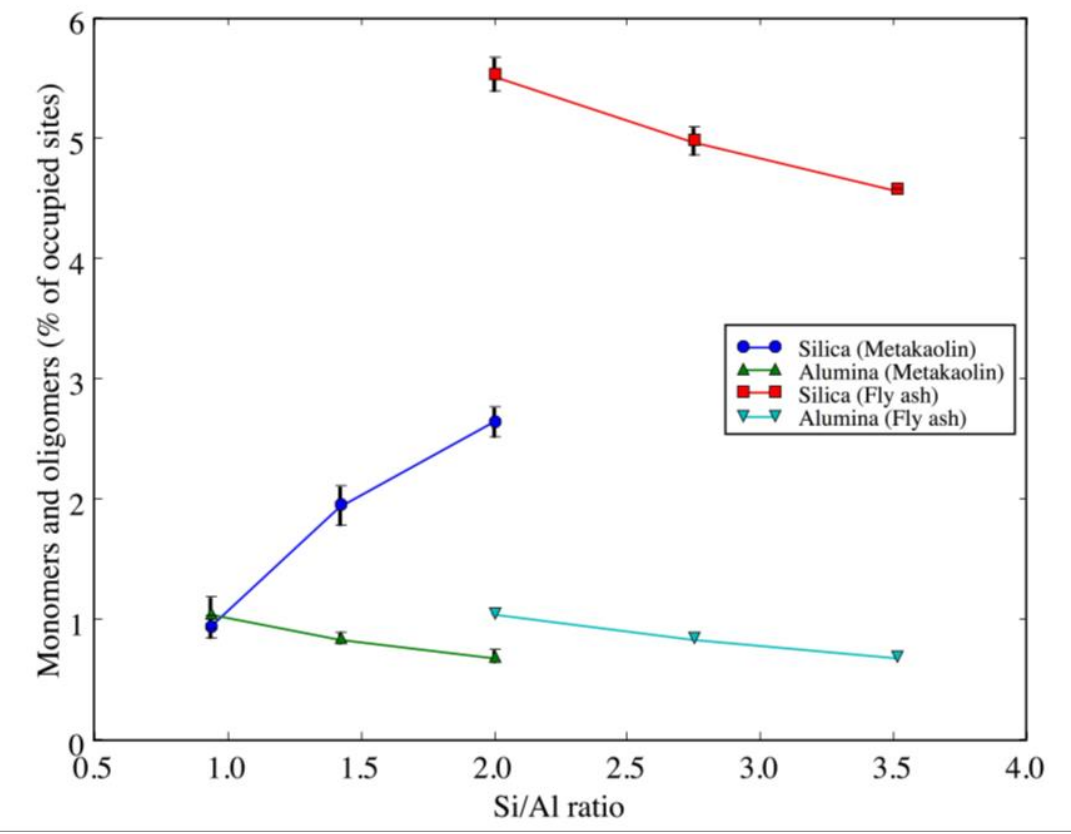

Figure. S.3. Concentration of monomers and oligomers (silica and alumina) in the pore solution of the final AAM gels according to the type of precursor (metakaolin and fly ash). The use of different activators (H-, H/S- and S-activated) impacts the overall $\mathrm{Si} / \mathrm{Al}$ ratio of the systems studied (see Table 2 in the main article for the $\mathrm{Si} / \mathrm{Al}$ ratios of the different AAM gels studied in this investigation). 


\section{Evolution of the Percentages of Si and Al Monomers in H-activated Metakaolin}

In Fig. 4 of the main article, a structural rearrangement is observed between the dissolution and condensation stage of the alkali-activation process. To explain this phenomenon, the evolution of the percentages of $\mathrm{Si}$ and $\mathrm{Al}$ monomers in the $\mathrm{H}$ activated metakaolin system is plotted in Fig. S.4 (the behavior of the other AAM systems is similar to the H-activated metakaolin system and hence not shown here). It is seen that at $10^{3}-10^{4}$ iterations, the amount of $\mathrm{Si}$ and $\mathrm{Al}$ monomers increases simultaneously, corresponding to a constant percentage of $\mathrm{Al}$ in the dissolving precursor particle (in Fig. 5 of the manuscript). However, although the amount of Al monomers continues to increase after $10^{4}$ iterations, the amount of Si monomers starts to decrease. This indicates that starting from $10^{4}$ iterations, $\mathrm{Al}$ monomers are still dissolving from the precursor, whereas $\mathrm{Si}$ monomers have reached their maximum extent of dissolution and begin to condense (back) onto the precursor particle. This signifies the drop in the Al concentration in the precursor particle in Fig. 5, until Al species have reached their maximum extent of dissolution from the precursor particle. The relatively stable size of the precursor particle as seen in Fig. 4 is hence due to the counteracting effects of $\mathrm{Al}$ dissolution and Si condensation.

The difference in the maximum extent of dissolution between $\mathrm{Si}$ and Al monomers stems from the interaction energy parameters, where the formation of Si-O-Si and Si$\mathrm{O}-\mathrm{Al}$ bonds are energetically favorable, but the formation of Al-O-Al bonds is not favorable. ${ }^{2}$ This means that Si monomers find it easier to form bonds on the surface of the precuror particle compared to Al monomers, which leads to a longer dissolution stage for the Al species. However, it has been experimentally observed that

preferential release of $\mathrm{Al}$ species occurs during dissolution of metakaolin. ${ }^{3}$ Because 
the occurrence of the structural rearrangement is based on the concurrent dissolution of both $\mathrm{Si}$ and $\mathrm{Al}$ species according to the above analysis, the structural rearrangement is possibly not reflecting the true reaction process.

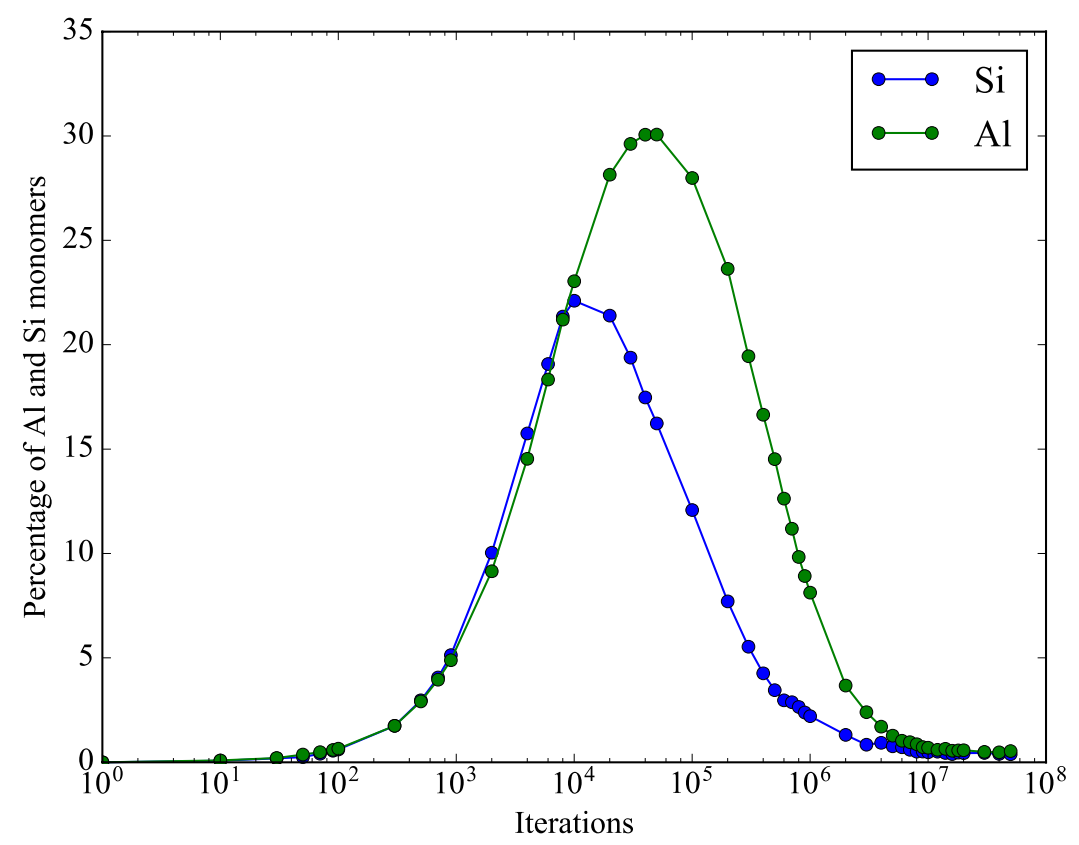

Fig. S.4. Evolution of the percentages of $\mathrm{Si}$ and $\mathrm{Al}$ monomers of $\mathrm{H}$-activated metakaolin 


\section{Dissolution Rate of Metakaolin and Fly Ash Precursor Particles}

To compare the dissolution behavior of different precursors, the data in Fig. 5 of the main article is grouped and replotted in Fig. S.5 below. Though subtle, it is seen that fly ash-based systems generally dissolve faster than metakaolin-based systems for all three alkaline solutions.

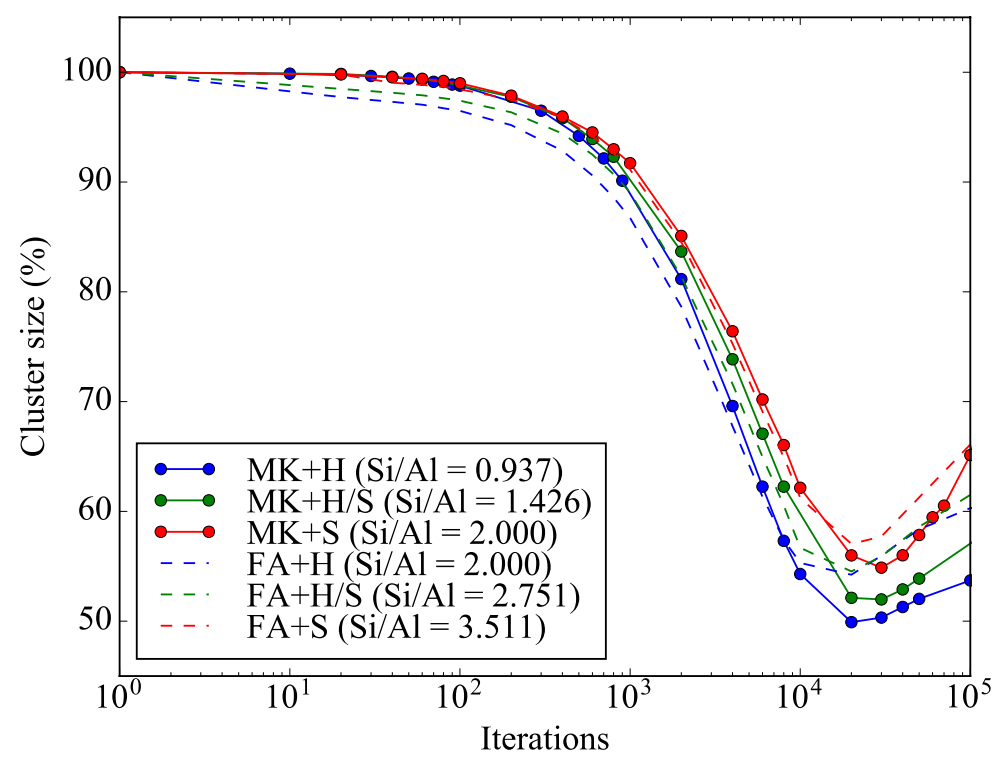

Figure. S.5. Size evolution of the largest particle (initially the metakaolin and fly ash precursor) with different activators during the dissolution stage. 


\section{Approximation of the Size of the Fly Ash Precursor Particle}

The distance between each $\mathrm{Si} / \mathrm{Al}$ atom can be estimated by the $\mathrm{Si}-\mathrm{T}$ ( $\mathrm{T}$ is $\mathrm{Si}$ or $\mathrm{Al}$ ) correlation from X-ray pair distribution function data of alkali-activated metakaolin, which is found to be $\sim 3.1 \AA \AA^{4,5}$ To simplify the calculation, assume that the particle is of spherical shape and consists of 29500 sites. Each site would then occupy a space equivalent to a cube with a side length of $3.1 \AA$, which is calculated below:

$$
(0.31 \mathrm{~nm})^{3}=0.03 \mathrm{~nm}^{3}
$$

The total volume, $\mathrm{V}$, of the sphere containing 29500 sites would be:

$$
0.03 \mathrm{~nm}^{3} \times 29500=885 \mathrm{~nm}^{3}
$$

Then we can calculate the radius of the sphere from the equation:

$$
\mathrm{V}=\frac{4}{3} \pi r^{3}
$$

where $r=5.96 \mathrm{~nm}$. So the diameter of the sphere is $11.9 \mathrm{~nm}$. Similarly, if the fly ash sphere consists of 26250 sites, the diameter would be $11.5 \mathrm{~nm}$.

\section{Connectivity $\left(Q^{n}, n=0-6\right)$ Distributions in the AAM Systems}

Fig. S.6 shows the $\mathrm{Q}^{\mathrm{n}}$ distributions of the six AAM systems investigated in the main article. It is seen that during dissolution $\left(0-\sim 10^{4}\right.$ iterations $), Q^{5}$ and $Q^{6}$ species rapidly decrease, accompanied by an increase in the amount of $\mathrm{Q}^{0}$ species. This indicates that the highly strained bonds in the metakaolin and fly ash precursor particles are broken, forming numerous monomeric species. After that, species with low connectivity $\left(Q^{0}, Q^{1}\right)$ decrease, while species with higher connectivity $\left(Q^{2}, Q^{3}, Q^{4}\right)$ increase, indicating that condensation and reorganization reaction occurs during the formation of alkali aluminosilicate gel. 
(a)

$\mathrm{MK}+\mathrm{H}$
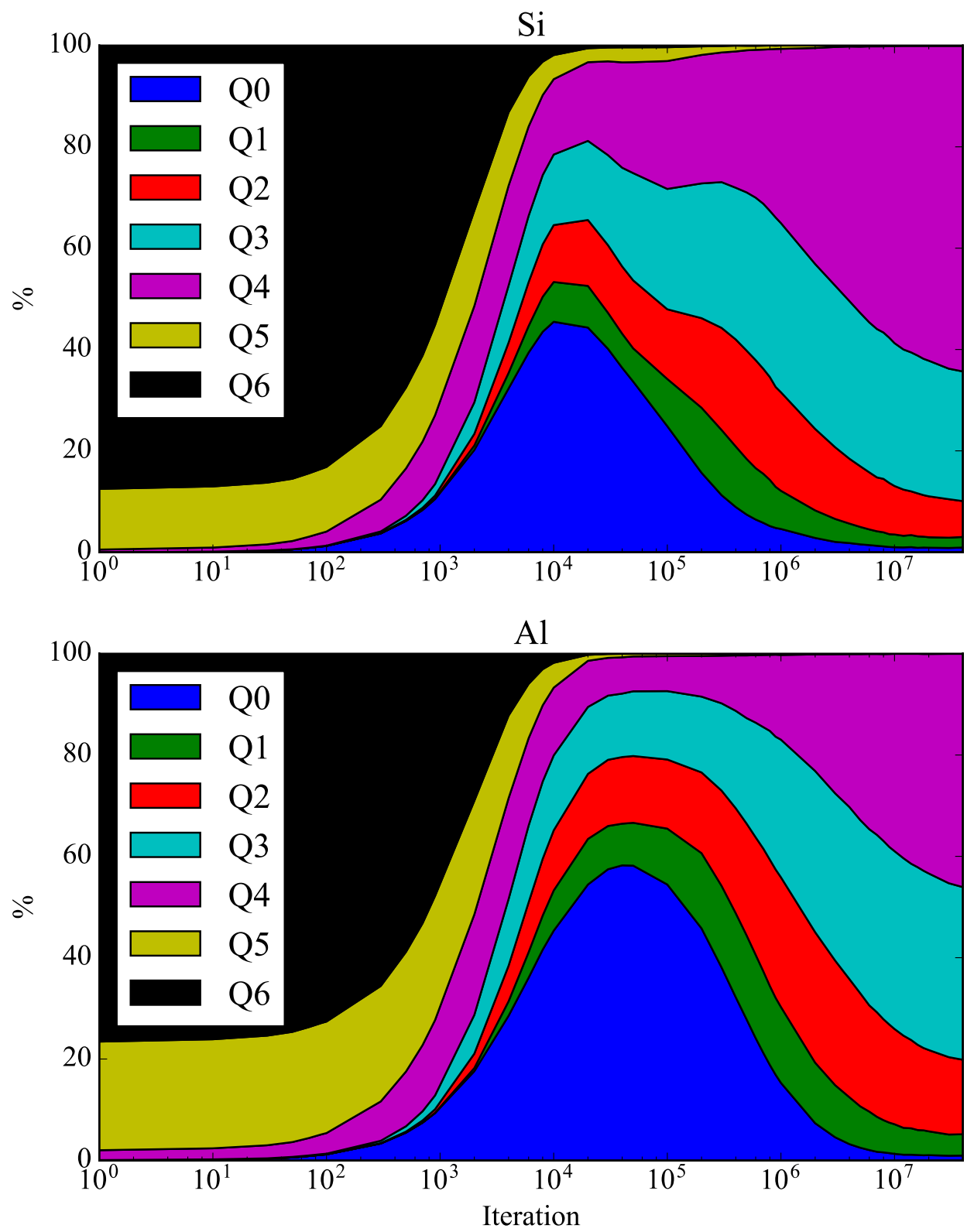
(b)

$\mathrm{MK}+\mathrm{H} / \mathrm{S}$
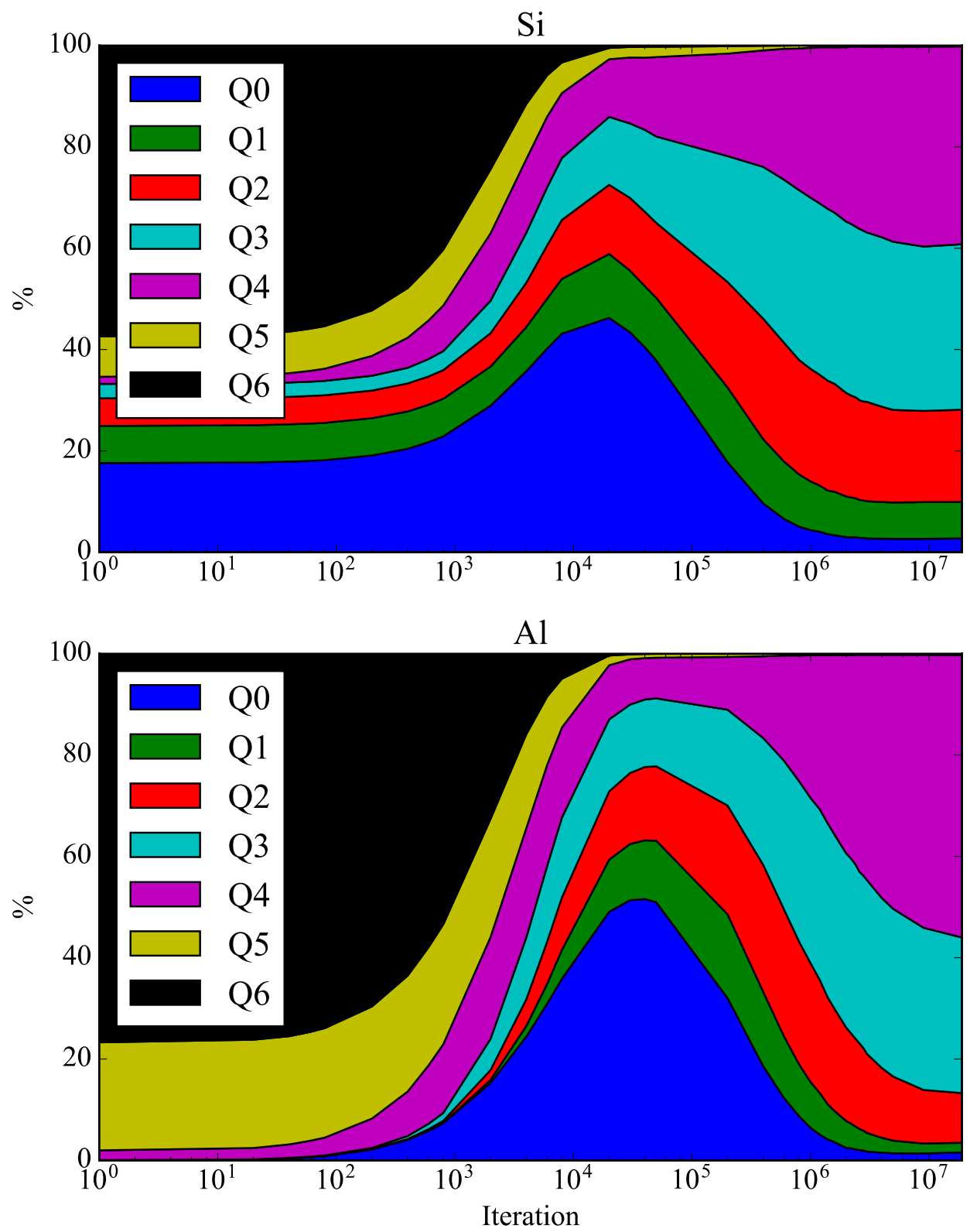
(c)

$\mathrm{MK}+\mathrm{S}$
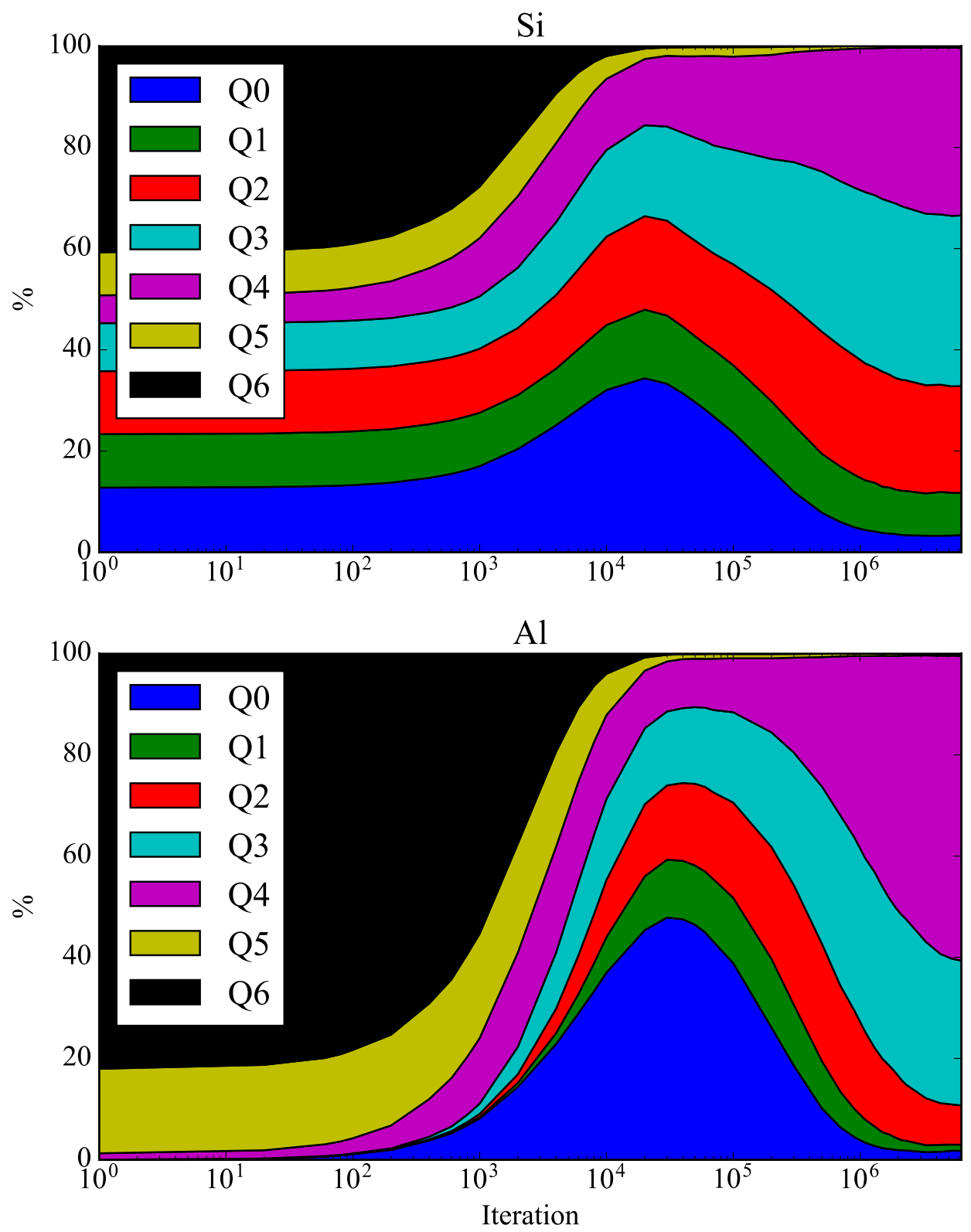
(d)

$\mathrm{FA}+\mathrm{H}$
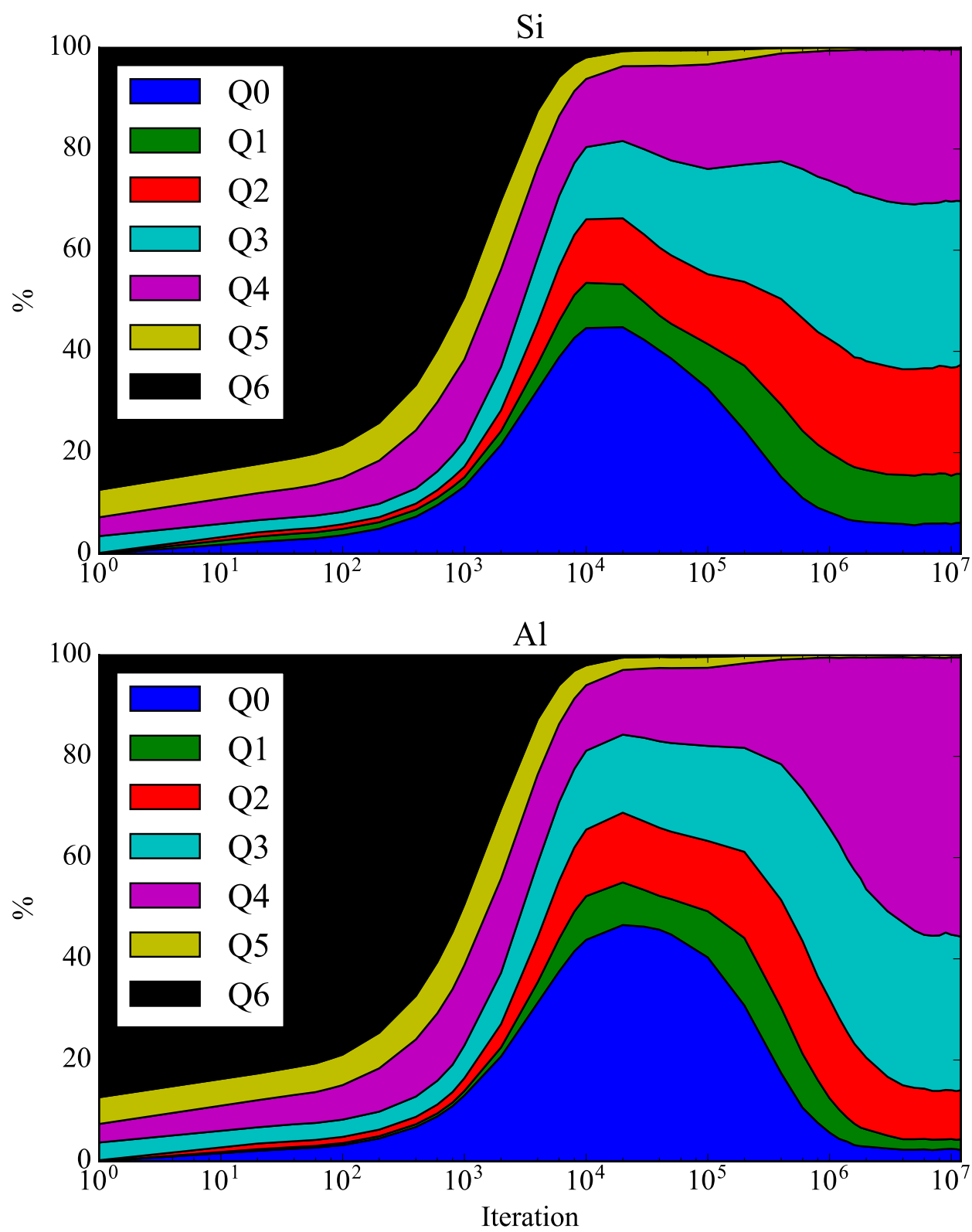
(e)

$\mathrm{FA}+\mathrm{H} / \mathrm{S}$
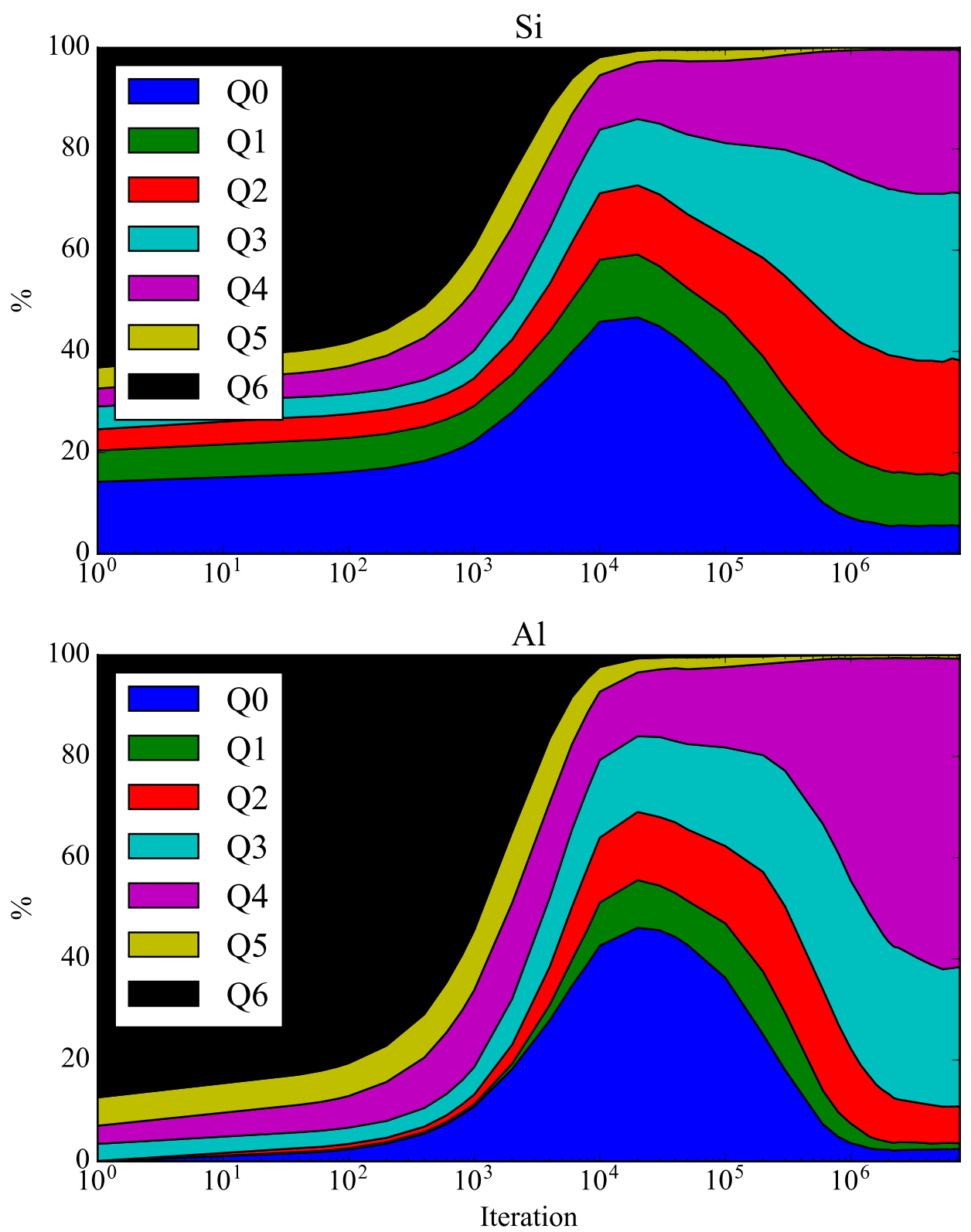

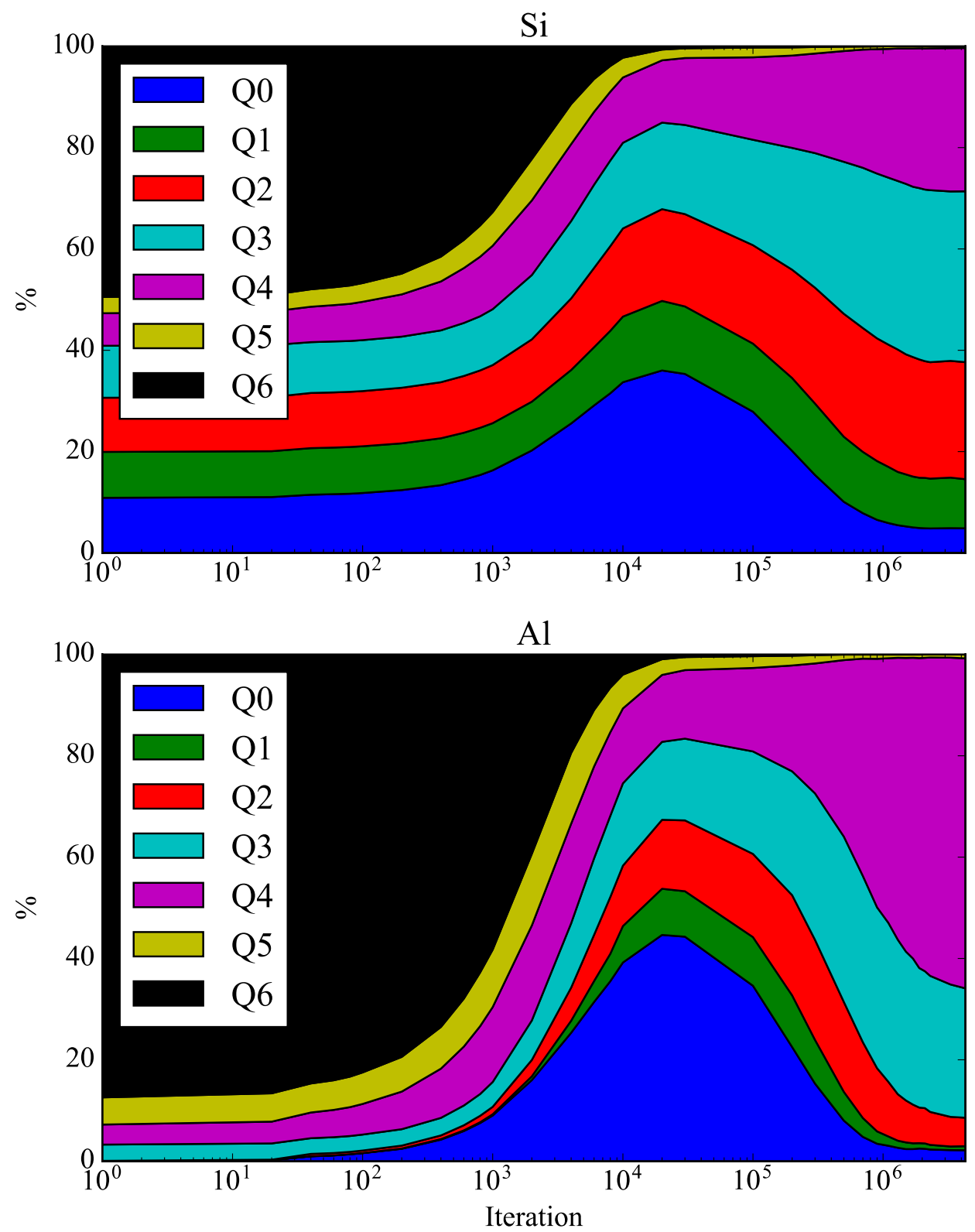

Figure. S.6. Connectivity $\left(\mathrm{Q}^{\mathrm{n}}, \mathrm{n}=0-6\right)$ distributions of silicate and aluminate species in (a) $\mathrm{H}$-activated metakaolin, (b) $\mathrm{H} / \mathrm{S}$-activated metakaolin, (c) S-activated metakaolin, (d) H-activated fly ash, (e) H/S-activated fly ash, (f) S-activated fly ash. 


\section{References}

(1) Zhang, Z.; Provis, J. L.; Wang, H.; Bullen, F.; Reid, A. Quantitative Kinetic and Structural Analysis of Geopolymers. Part 2. Thermodynamics of Sodium Silicate Activation of Metakaolin. Thermochim. Acta 2013, 565, 163-171.

(2) White, C. E.; Provis, J. L.; Kearley, G. J.; Riley, D. P.; van Deventer, J. S. J. Density Functional Modelling of Silicate and Aluminosilicate Dimerisation Solution Chemistry. Dalton Trans. 2011, 40, 1348-1355.

(3) Bauer, A.; Velde, B.; Berger, G. Kaolinite Transformation in High Molar KOH Solutions. Appl. Geochem. 1998, 13, 619-629.

(4) White, C. E.; Page, K.; Henson, N. J.; Provis, J. L. In Situ Synchrotron X-Ray Pair Distribution Function Analysis of the Early Stages of Gel Formation in Metakaolin-Based Geopolymers. Appl. Clay Sci. 2013, 73, 17-25.

(5) White, C. E.; Provis, J. L.; Bloomer, B.; Henson, N. J.; Page, K. In Situ X-Ray Pair Distribution Function Analysis of Geopolymer Gel Nanostructure Formation Kinetics. Phys. Chem. Chem. Phys. 2013, 15, 8573-10. 